\title{
Ajuste estructural y política en la Provincia de San Juan. El primer sanjuanazo
}

Structural Adjustment and Politics in the Province of San Juan. The First Sanjuanazo

\section{Horacio Cao}

Dr. en Ciencias Económicas (UBA). Investigador del Instituto Universitario Ortega y Gasset de la Argentina

horaciocao33@hotmail.com

al "Chango" Illanes

a Carlos Yanzón

In memoriam

\section{Recibido}

24.12 .12

\section{Aprobado}

12.3.13

\section{Resumen}

Analizamos en este trabajo las tensiones y conflictos que tuvieron lugar a mediados de la década de 1990 en la Provincia de San Juan, que culminaron con las masivas movilizaciones sociales conocidas posteriormente como "primer sanjuanazo" en 1995. El texto enfoca el modo en que transformaciones en la estructura socioeconómica de la provincia, sumadas al surgimiento de nuevos actores políticos -desde las intervenciones militares hasta los técnicos del ajuste estructural posterior- crearon las condiciones para la profundización del malestar social y la inestabilidad política que condujeron al "sanjuanazo" -un encadenamiento de hechos y circunstancias que también se registró, hacia la misma época, en otras provincias argentinas. Si bien el sanjuanazo tuvo una clara vinculación con las políticas de ajuste estructural impuestas en la época, sus modalidades concretas, que lo diferencian de ellas son el producto de las características específicas, estructurales, sociales y político-institucionales, que se configuraron en San Juan en las décadas previas. $\mathrm{El}$ análisis de fuentes periodísticas y entrevistas en profundidad realizadas a muchos de los protagonistas de aquellas jornadas permite develar una trama que, además de explicar los sucesos, echan luz sobre las características centrales de la sociedad regional. Palabras clave: federalismo, San Juan, sanjuanazo, ajuste estructural, neoliberalismo. 


\begin{abstract}
We analyze in this piece the tensions and conflicts that took place in the mid-1990s in the province of San Juan, which culminated in the massive social mobilizations later on known as the first sanjuanazo. Focusing on the way the transformations in the province's socioeconomic structure, added to the emergence of new political actors -including military interventions and delegates as well structural adjustment technicians both coming from the central government- building for the conditions for increasing social protests together with deepening political instability thus leading to the sanjuanazo, in a way which in more than one point resemble social upheavals experienced in other Argentine provinces by the same time. While an effect and a reaction to Neoliberal structural adjustment policies, the specific traits differentiating it from the latter are interpreted as the effect of the particular structural, social, political and institutional conditions which evolved in San Juan over the previous decades. Relying on indepth interviews to many of the actors directly involved in both sanjuanazo and its aftermath, as well on regional newspapers archives, the article provides, in addition to an interpretation of the events under scrutiny, a close approach to the unfolding of a regional society.
\end{abstract}

Keywords: federalism, San Juan, sanjuanazo, structural adjustment, neoliberalism.

\title{
Introducción
}

A lo largo del presente trabajo analizamos los conflictos y turbulencias ocurridos a mediados de los años noventa en la Provincia de San Juan, parte de lo que se conoce como "área periférica" de la Argentina. En particular, describiremos lo que se conoce como Primer Sanjuanazo, los sucesos ocurridos en el año 1995 en el marco de la profunda recesión que a lo largo y ancho del país disparó el efecto tequila. ${ }^{1}$

Como no ocurría desde principios del siglo XX, durante la década de 1990 los escenarios provinciales ganaron en autonomía e importancia. Paralelamente, las rígidas condiciones que establecía la convertibilidad y la liquidación de la inflación, generaron un escenario financiero y fiscal volátil, que al poner en riesgo el pago de salarios en el empleo público, amenazó la gobernabilidad provincial. Fue así que en varias provincias -Santiago del Estero, La Rioja, Jujuy, Río Negro entre otras- se sucedieron explosiones 
sociales y políticas, verdaderas puebladas que daban cuenta de las tensiones que estaba generando el ajuste estructural.

En tal sentido, y más allá de la importancia que pueda tener una crónica de los hechos, creemos que el texto es relevante para analizar algunos elementos sociopolíticos de la sociedad regional que con la crisis salieron a la luz y, asimismo, observar cómo estas turbulencias guardan relación con los cambios de fondo que se estaban desarrollando en el país. En particular, consideramos que son parte del proceso de construcción de un nuevo acuerdo federal hacia la periferia -que se estaba erigiendo después de que se desestructurara aquél que se centraba en las economías regionales- y de un nuevo modelo de liderazgo provincial, consecuencia del proceso anterior, que se asentaba sobre el gasto público y el aparato administrativo provincial. ${ }^{2}$

Para tratar el tema, este trabajo comienza con una breve descripción de la Provincia de San Juan, en tanto parte de la histórica periferia extra pampeana, y de su economía regional: la vitivinicultura. En la siguiente sección se establece cuál fue el impacto en esta provincia de las políticas de ajuste estructural a partir de su condición de estado miembro de la federación argentina y parte de la región de Cuyo, que se había especializado en la producción vitivinícola. En la tercera sección, que es el núcleo central de este trabajo, se presenta cómo se había ido construyendo la matriz política provincial hacia mediados de la década de 1990 y de qué forma se fueron configurando los elementos que terminarían generando la explosión social conocida como sanjuanazo. Por último se hace una semblanza de su impacto en la coyuntura política y cómo su traza dejó una marca indeleble en la política provincial.

\section{La provincia de San Juan}

\subsection{San Juan, provincia de la periferia}

Cualquier visión que se haga de la totalidad del país no puede pasar por alto el nivel de heterogeneidad y desigualdad que lo recorre en todos los ámbitos de su vida social. Diferentes trabajos han dado cuenta de esta situación, dividiendo a la República Argentina país en tres áreas: ${ }^{3}$

Área periférica: Comprende a las provincias de la franja norte y centro/oeste del país, caracterizándose por la importante presencia de formas de producción no capitalistas y por haber sido, durante buena parte del último siglo, la fuente de las migraciones internas. Esta situación las lleva a exhibir ingresos per cápita e índices sociales ostensiblemente menores a los del resto del territorio nacional.

Área central: Se caracteriza por contener jurisdicciones que presentan una concentración de población y un aparato productivo de dimensiones, modernidad y dinamismo muy superior al que se observa en otras áreas del territorio, tanto es así que en un área 
que representa aproximadamente en el $20 \%$ de la superficie nacional se concentra el $65 \%$ de la población y el 75\% del PBI.

Área mixta: Ubicadas al sur del país se caracterizan por la baja densidad poblacional relativa, fruto del tardío proceso de ocupación Dentro de su aparato productivo se destaca la existencia de algunos emprendimientos muy desarrollados -como el petrolero y el turístico- junto a otros - explotaciones ganaderas extensivas- que presentan condiciones asimilables a las del área periférica.

\subsection{San Juan y la vitivinicultura}

Sin ser el objetivo de este escrito, y con el único fin de dar al lector un encuadre general, comencemos comentando muy brevemente los procesos que explican la pertenencia de la Provincia de San Juan al grupo de jurisdicciones que componen la llamada "área periférica”. Esta pertenencia ocurre desde la misma organización nacional, ocurrida en el último tercio del siglo XIX, cuando el emprendimiento vitivinícola comienza a desplazar a la ganadería como principal actividad económica provincial. En este proceso fue clave la llegada del ferrocarril que vinculó a San Juan con el dinámico mercado pampeano, rompiendo la secular orientación de esta provincia hacia los mercados trasandinos. ${ }^{4}$ La producción de vino adquirió las características propias de lo que en Argentina se denominó “economías regionales": un producto elaborado casi exclusivamente para el mercado interno, protegido de la competencia internacional y de otras regiones del país y con subsidios que permitían la reproducción de minifundios vitícolas y pymes bodegueras, a la vez que garantizaban rentas extraordinarias a productores de mayor escala y avance tecnológico.

Alrededor del proyecto vitivinícola, y de los procesos de democratización política de principios del siglo XX, surgió el Partido Bloquista -liderado por los hermanos Federico y Aldo Cantoni- como escisión de la Unión Cívica Radical. Este partido, que habrá de protagonizar fuertes choques con el Gobierno Nacional, propugnó importantes y novedosas medidas sociales y políticas; por ejemplo, una fiscalidad progresiva que la burguesía provincial catalogó como "confiscatoria". La hegemonía del Partido Bloquista se mantuvo, aunque con altibajos, durante casi todo el siglo XX, erigiéndose en uno de los partidos provinciales más trascendentes de la Argentina. Como casi todas las agrupaciones de este tipo, y a despecho de antecedentes ideológicos cercanos a la doctrina socialista, a partir de la llamada Revolución Libertadora (año 1955), el bloquismo tendió a articularse con gobiernos militares y partidos conservadores. Esta nueva versión del partido de la estrella -como se lo conoce en la provincia- es paralela al ascenso a su conducción de Leopoldo Bravo, quien fuera varias veces gobernador provincial, tanto por voto popular como por medio de designaciones hechas por dictaduras militares. 
La mutación de partido popular a representante de la élite vitivinícola se explica a partir de los cambios que comenzaron con la crisis de los años treintas y que se consolidaron con el peronismo. En tal etapa, se estableció una nueva división del trabajo NaciónProvincias que llevó a las estructuras políticas subnacionales a reconvertirse en gestoras ante las estratégicas oficinas reguladores -en nuestro caso, el hoy Instituto Nacional de Vitivinicultura- que funcionaban en la órbita nacional. En este nuevo ámbito de acción, la disputa ya no se daba hacia el interior provincial, sino frente a otros actores regionales por los cupos de producción, subsidio y financiamiento a través de instrumentos tales como precio de vino de traslado, tamaño del área sembrada, redescuentos a bancos provinciales, etc. En estas disputas, como lo aprendió rápidamente Leopoldo Bravo, era tan o más importante los actores corporativos -vinculados a los citados gobiernos militares o a partidos conservadores que los nucleaban- que los partidos que pugnaban por la voluntad popular (véase Cao y Rubins, 1996).

Los procesos de ajuste estructural que se desarrollaron de manera sistemática a partir del golpe de estado de 1976 -desregulación, apertura externa, reducción de subsidios del Estado Nacional, etc.- indujeron un generalizado empobrecimiento de la provincia. Ello fue así porque su despliegue provocó la fractura de las llamadas economías regionales, entre ellas, la del complejo vitivinícola. ${ }^{5}$

Estos procesos, como veremos, nos son ajenos al inicio de la decadencia del bloquismo como partido hegemónico.

\section{San Juan en la era del ajuste estructural}

\subsection{Las nuevas condiciones: crisis vitivinícola e inflación estatal}

La nueva etapa económica, social y política que se abre hacia mediados de los años setenta es particularmente desfavorable para la Provincia de San Juan. Su aparato productivo de se basaba casi totalmente en la vitivinicultura, y a partir de esos años comienza una dolorosa reestructuración de la actividad.

Una imagen de la dimensión del proceso de reconversión está dada por el descenso de la producción global, que pasó de un pico productivo de más de 28 millones de hectolitros en el año 1967 a bastante menos que la mitad, 12,5 millones de hectolitros, en el año 2000 (OECEI, 1974 e INV, 2002).

En este proceso, uno de los segmentos más castigados fue el de los trabajadores rurales que, en términos de la población provincial, descendieron en dos tercios en aproximadamente treinta años (Cuadro $\mathrm{N}^{\circ} 1$ ). 
Cuadro $\mathbf{N}^{\mathbf{0}} 1$

Población y Trabajadores Rurales de la Provincia de San Juan

En número y porcentaje de trabajadores rurales en la población

Años 1969-70 y 1988-91

\begin{tabular}{|l|r|r|}
\hline \multicolumn{1}{|c|}{ Provincia de San Juan } & \multicolumn{1}{c|}{$\mathbf{1 9 6 9 - 7 0}$} & \multicolumn{1}{c|}{$\mathbf{1 9 8 8 - 9 1}$} \\
\hline Población & 384.284 & 525.488 \\
\hline Trabajadores Rurales & 47.757 & 22.737 \\
\hline \% Trabajadores rurales en Población & $12,4 \%$ & $4,3 \%$ \\
\hline
\end{tabular}

Fuentes: Censos Nacionales de Población y Vivienda 1970 y 1991 y Censos Agropecuarios 1969 y 1988.

De igual manera, las unidades productivas rurales sufrieron un agudo descenso. Entre los Censos agropecuarios de 1969 y 2002, las EAP's (Explotaciones Agropecuarias) de la provincia descendieron más de un $45 \%$; por su parte, el número de viñedos disminuyó a la mitad entre 1979 y el año 2000 (INV, 2002).

No sólo hubo crisis en el segmento agrícola; la producción industrial también recibió los embates de los cambios en la situación productiva. En este aspecto, los emprendimientos del rubro "Elementos alimenticios y bebidas" se redujeron en cantidad y en personal ocupado en aproximadamente un 20\% en el espacio intercensal $1974-1994$.

Un último elemento que quiere citarse, en este brevísimo repaso de la crisis vitivinícola, tiene que ver con la paralela desaparición de una gran cantidad de firmas que funcionaban en los principales centros de consumo (ciudades de Buenos Aires, conurbano bonaerense, Rosario y Córdoba) y que desarrollaban tareas de fraccionamiento, embotellado y comercialización de vinos. Este era el punto de contacto entre agentes económicos de origen provincial con otros cuyos principales intereses se encontraban en lo que describimos como área central.

En resumidas cuentas, los datos presentados están mostrando el fin de un cierto patrón productivo caracterizado por:

- Un entramado regulatorio de base nacional que garantizaba la supervivencia del emprendimiento como un todo.

- Procesos productivos que involucraban la reproducción de pequeños y grandes propietarios rurales vitícolas e industriales vitivinícolas, y

- Un ámbito de articulación donde se anudaban intereses regionales con otros extra regionales. 
En este ordenamiento las contradicciones dentro del emprendimiento vitivinícola (en función de la posición en la estructura productiva, de la escala de producción, de la articulación entre viñateros y bodegueros, etc.) tendían a quedar desdibujadas detrás del objetivo común de todos los agentes económicos de competir con actores de otras economías regionales en la obtención de regulaciones favorables por parte del gobierno nacional (protección arancelaria, subsidio bancario y estatal, regulación del área sembrada, etc.).

La crisis abierta hacia los años setentas condujo a que esta forma y estos objetivos de la política provincial fueran quedando perimidos a partir de la violenta reconversión que reposiciona a la vitivinicultura en el tablero provincial. Los actores rurales ligados a la producción vitícola y los urbanos vinculados a los emprendimientos bodegueros debieron amoldar su situación a la nueva lógica reinante, bajo peligro de desaparecer.

En efecto, el gran propietario, ligado a la clase tradicional sanjuanina, que desarrolla una relación personal con sus empleados, es reemplazado por el productor internacionalizado que a veces ni conoce el campo en donde ha invertido. El viejo puestero es suplantado por la cuadrilla. Así, los agentes dinámicos del mundo rural pasan a estar compuestos en casi todos los casos por población de origen urbano, que puede ir al campo más o menos asiduamente, pero que generalmente vuelve cotidianamente a sus hogares en la ciudad. ${ }^{7}$ A diferencia de lo que ocurría en el modelo anterior, estos agentes productivos, que junto con los mineros representan a los sectores más dinámicos y concentrados de la economía provincial, tienen una muy baja vinculación con el Estado provincial.

¿Y los que por escala o falta de capital no pudieron reconvertirse? En general eran ignorados por los decisores de la época. En una serie de entrevistas ${ }^{8}$ realizadas a funcionarios que cumplieron funciones de rango ministerial durante los años noventas pudo observarse el escaso interés que la situación del sector promovía en los informantes. Ante la insistencia de nuestras preguntas agregaban alguna apostilla muy escueta donde los definían como “...proyectos más bien ligados a la subsistencia que proyectos ligados al desarrollo capitalista” (a: 80) o describían los pedidos de “... créditos para cosecha y acarreo, regulaciones variadas, exenciones impositivas o precio sostén...” (g: 102).

Estas demandas, como también lo hacían notar, "forman parte del folklore provincial", pero "la verdad es que consiguen poco. La situación global hace que la provincia no tenga instrumentos para atender a este sector..." (g: 102). También estaba presente en la visión de los actores políticos y sociales, que estos actores se habían “especializado” en la gimnasia política y administrativa para el acceso a subsidios, pasando a un segundo plano sus esfuerzos en el plano productivo.

Otro subproducto de la crisis -con múltiples efectos sobre diferentes espacios de la vida política provincial- es la concentración de población en el Gran San Juan. Este 
fenómeno se origina en las migraciones que la crisis de la vitivinicultura impulsa desde áreas rurales y ciudades intermedias y su efecto se potencia por la dilución del efecto de atracción de población de la región pampeana.

La confluencia de estos hechos terminó generando que, en la mancha urbana del valle de Tulum - Ullun - Zonda, que no ocupa más del 2 o 3\% de la superficie provincial, se concentre más del 90\% de la población (Censo 2001). En este proceso, esta mancha literalmente ha engullido algunos departamentos que otrora tenían vida propia (Ullum, Caucete, Pocito, Zonda, etc.) y que ahora se han convertido en espacios periurbanos con importante presencia de población de bajos recursos. ${ }^{9}$

Este es un fenómeno relativamente nuevo en la provincia; hacia los años setentas las Villas Miserias eran casi inexistentes en San Juan y la pobreza extrema se vinculaba principalmente con las familias rurales. En la época en que se desarrollaron los acontecimientos que vamos a comentar, estaba en pleno crecimiento un vastísimo cinturón de asentamientos precarios. Para dar una idea de su tamaño, uno sólo de estos asentamientos, la Villa del Nylon llegó a concentrar más de 10.000 habitantes, y era considerada la población joven más grande de la Región de Cuyo.

Ante esta situación global -desaparición de buena parte del aparato productivo, situación de enclave de agentes económicos que logran una reconversión exitosa, concentración de población pobre y lábil en cinturones periurbanos- el accionar de la Administración Pública surge como el eje vertebrador de la vida provincial. Es que su envergadura la convierte en el factor clave para sostener un cierto nivel de actividad, empleo y demanda agregada, como para garantizar los ingresos de gran cantidad de familias.

En efecto, uno de los aspectos que apuntalaba la centralidad de la Administración Pública, era el rol que ocupaba dentro de un mercado de trabajo agudamente deprimido por los procesos de reconversión. Así, el empleo público concentraba más del 36,5\% de los ocupados, guarismo que da una idea del impacto de este tipo de empleo en la provincia, casi un $40 \%$ superior al valor que este mismo registro tiene en la Provincia de Buenos Aires, a pesar de que San Juan tiene una tasa de actividad menor (Censo Nacional de población, 2001).

La presión para el ingreso en la Administración Pública era superlativa; y esto no sólo por las tasas de desocupación sino también a una brecha cada vez mayor entre las características del sistema privado y el sistema público. Las políticas pro mercado no habían hecho más que generar reglas crecientemente "salvajes" en la actividad privada, con tendencias a la precarización y sobreexplotación de la fuerza de trabajo; mientras que en el sector público se mantenían las condiciones de trabajo y la duración de la jornada laboral vigentes en la etapa del Estado Benefactor. Además, se pagaban mejores salarios 
y se había mantenido una gimnasia sindical que en alguna medida protegía y ampliaba derechos.

Para los que no podían acceder a un empleo, la incorporación a diferentes programas de carácter asistencial ocupaba el lugar siguiente en la escala de interés de buena parte de los sanjuaninos. De hecho, los programas de emergencia laboral -en aquella época, los más conocidos eran los Planes Intensivos de Trabajo (PIT) y Planes Trabajar- o la asistencia alimentaria resultaban cruciales para la supervivencia de buena parte de la población.

Puestos los elementos de esta forma, está claro que la Administración Pública, y su decisivo papel en el sostén de un cierto nivel de demanda, inversión y mano de obra ocupada pasa a ser la nueva clave de la política, más que la alianza con grandes propietarios y bodegueros para pelear en el Estado Nacional.

\subsection{La relación con el gobierno nacional ${ }^{10}$}

Como en toda estructura federal, un elemento clave de la política provincial tiene que ver con los diferentes modelos de relación que establecieron los gobiernos provinciales con las autoridades nacionales. En este aspecto, el bloquismo tenía como uno de sus principales activos el haber logrado construir una red de relaciones con actores sociales y políticos que actuaban en el ámbito nacional.

Bajo la tutela del largo y legendario liderazgo de Leopoldo Bravo, los funcionarios bloquistas se presentaban como los gestores políticos más adecuados a partir de su capacidad de lobby frente a actores relevantes del poder nacional -militares, sindicalistas, empresarios, representantes corporativos, periodistas, dirigentes de otros partidos, etc.- y de su reconocida capacidad de seducción, tensión, enfrentamiento y negociación con funcionarios del gobierno central.

Sus logros cotidianos en la defensa de la vitivinicultura provincial, la obtención de cupos en la promoción industrial, el coeficiente de coparticipación federal de impuestos que tiene la provincia, daban cuenta de la capacidad de este grupo político para representar los intereses provinciales.

Durante el gobierno de la Unión Cívica Radical (1983-1989) estos atributos pasaron a ser, paulatinamente, menos importantes, pero de alguna forma se compensaron por el papel que cumplieron los dos senadores bloquistas ante la debilidad del oficialismo nacional en la Cámara alta. De hecho, tal debilidad posibilitó que el bloquismo (en conjunto con otras agrupaciones provinciales) definiera algunos elementos clave de la agenda legislativa, lo cual, con la experiencia que en estas lides tenían estos partidos, fueron aprovechadas para obtener importantes concesiones. Para decirlo de una manera directa, cada vez que el ejecutivo necesitaba aprobar una ley, como los votos de estos 
senadores servían para inclinar la situación en un lado u otro, era común que obtuvieran beneficios extraordinarios como contrapartida por acompañar al bloque radical.

Con la llegada de Carlos Saúl Menem a la presidencia de la Nación (1989), el oficialismo nacional dejó de tener dificultades en la Cámara Alta (en donde el Partido Justicialista tenía mayoría propia), por lo que los senadores bloquistas perdieron casi todo su valor político. Fue como un preanuncio de que la dilatada hegemonía de este partido provincial estaba llegando a su fin.

El gobierno del Lic. Jorge Escobar (que asumió por primera vez en 1991) redefinió la relación de la provincia con las autoridades nacionales, presentándose ya desde la campaña electoral con un alineamiento absoluto con el presidente de la Nación y su poderoso Ministro de Economía (Domingo Cavallo).

El nuevo gobierno de San Juan -como casi todos los oficialismos de las provincias periféricas de la época- estableció como una de sus principales prioridades obtener la mayor cantidad posible de transferencias desde el gobierno nacional. Así, construyó un patrón de sobreasignaciones per cápita que tendría, hacia el final del gobierno de Escobar, un nivel del orden del $40 \%$ superior al que obtenían las provincias del área central (Presupuesto Nacional, 1999).

Ahora bien, ¿En qué medida el alineamiento de Escobar permitió diseñar este patrón? Nuestros informantes consideraron de manera casi unánime que esta situación fue clave. Reproducimos en extenso sus respuestas pues son particularmente reveladoras de la situación: "Nosotros teníamos una carta de presentación inmejorable, que era que estábamos alineados con Menem (...) Cuando venía alguien de San Juan, la carta de presentación era Escobar - Menem. Esto era sabido, incluso en los niveles más bajos” (f: 95). "Bueno, yo recuerdo que venir de San Juan era una cuestión muy importante, nos ponían alfombra roja... estábamos jugando en primera" (a: 78). "La provincia de San Juan era muy bien vista en esa época (...) había un muy buen feeling entre el gobierno nacional y el gobierno provincial, entonces daba gusto ir a cualquier despacho nacional (...) cuando uno iba a la oficina de algún Ministerio veía las antesalas que les hacían hacer a otras provincias; pero llegaba uno de San Juan y era al primero que atendían" (h: 104/105). "Tener afinidad política ayudaba a tener buena relación, a conseguir recursos. Hay un esquema de trabajo, pero si vos tenés acercamientos, algún tipo de relación política, como pasó con Escobar y Menem, eso siempre ayuda" (c: 88). "Éramos los niños mimados del gobierno nacional, por lo tanto era poco el esfuerzo para entrar a un despacho, para tener acceso al ministro...” (f: 95). "Durante mi gestión, el gobernador era una persona con mucha llegada a la Presidencia de la Nación y con amigos en todo el esquema del gobierno nacional (...) Estas relaciones... me sirvieron (...) con mi contraparte nacional (i: 108). 
La fluida articulación Nación-Provincia de San Juan se basaba prioritariamente en patrones de lealtad diferentes a la continua tensión-distensión de la etapa bloquista. Como ejemplificó un entrevistado al referirse a las posibilidades de negociar un acuerdo en el máximo nivel: "No ofrecíamos nada porque no teníamos conflicto a solucionar. No podíamos proponer alinearnos a una política porque ya lo estábamos” (f: 95).

De esta manera los gestores de la continuidad del emprendimiento vitivinícola se convierten en negociadores de crecientes transferencias financieras y de bienes - programa. Nótese que, por un lado, cambian los actores sociales que sostienen la política provincial, ya que de agentes económicos capaces de articularse para desempeñar una producción se convierten en actores políticos que gestionan recursos para el estado provincial. Por otro, que se acentúa la tendencia hacia un creciente pragmatismo en los oficialismos provinciales; mientras se envíen crecientes transferencias cualquier política nacional podrá ser apoyada.

Para el gobierno federal, por su parte, el poder formal y real que habían acumulado las provincias las convertía en aliadas cruciales a la hora de garantizar la continuidad del proceso de ajuste estructural. En línea con conseguir su sostén, desarrolló un tipo de articulación basada en el apoyo político de parte de las provincias periféricas a cambio de transferencias financieras o de bienes y servicios.

Las diferencias de escala hicieron que este mecanismo se desarrollara con especial facilidad en el caso de las Provincias del área periférica. Para decirlo de manera directa: una suma de dinero que en términos relativos podía ser poco significativa para el presupuesto federal representaba, para cualquier provincia periférica, un elemento determinante de su situación fiscal y/o económica. Por otro lado, el alineamiento provincial (votos en el Congreso de la Nación, apoyo en la interna partidaria, reducción del nivel de enfrentamiento interpartidario, etc.) era medular para el gobierno central, mientras que para la provincia adoptar una política independiente tenía, potencialmente, pocos beneficios. ${ }^{11}$

Según los entrevistados, el Gobierno de San Juan se habría mostrado muy hábil para alinearse y realinearse de acuerdo a las vicisitudes que ocurrían en el ámbito nacional. De esta forma, más allá de la invariable referencia a Menem, la articulación con otros actores del ámbito nacional fueron cambiando de acuerdo a la situación que ellos iban teniendo. Así, el alineamiento Menen - Cavallo de 1991, se convierte en Menem - Eduardo Menem en 1995 y posteriormente Menem - Corach. Es notorio cómo estos realineamientos van generando cambios en el acceso a fondos; así desde 1995 hasta que Escobar finalizó su mandato en 1999, los ATN remesados a San Juan pasaron de 2,6 millones a \$27,7 millones; lo que elevó la participación de la provincia en la distribución de $0,6 \%$ en 1994 a 6,5\% en 1999. Estos fondos son manejados por el Ministerio del Interior, y muestran cómo subieron las acciones del gobernador Escobar en esta jurisdicción a 
partir de la ruptura con el Ministro Cavallo y el acercamiento a los contendores del Ministro de Economía.

\section{Transferencias de ATN. En millones de \$ (eje izquierdo) $y \%$ (eje derecho) del total de transferencias \\ Provincia de San Juan. Años 1991 - 1999}

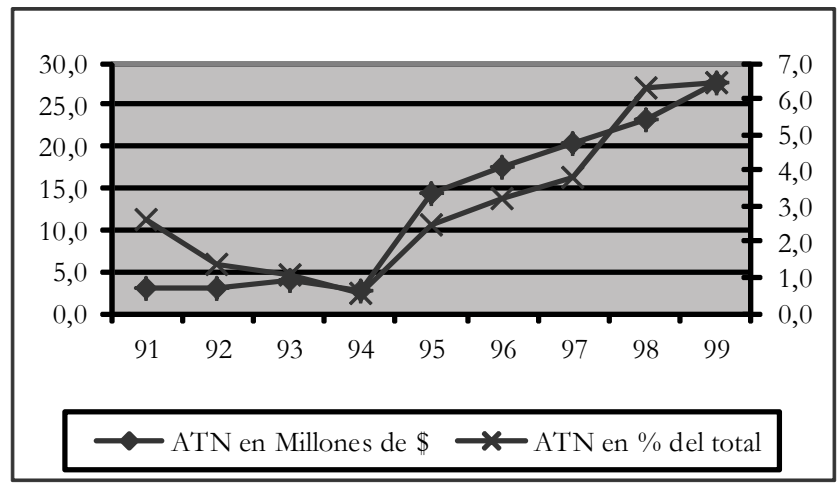

Fuente: Elaboración propia sobre datos de ProvInfo (2004)

Estos realineamientos no eran neutros en términos de las políticas que se impulsaban ni en cuanto a los equilibrios internos del propio gobierno provincial. Conviene retener estos elementos, ya que son cruciales para comprender los hechos que desembocaron en el sanjuanazo.

\section{Las turbulencias}

\subsection{La política sanjuanina desde el retorno de la democracia}

Hacia principios de los '80, cuando las autoridades del autodenominado "Proceso de Reorganización Nacional” observaron que su poder político comenzaba a debilitarse, se dieron a la tarea de intentar organizar una estructura político partidaria afin que empezara a trabajar sobre la hipótesis de una transición controlada. En línea con este objetivo se produce una serie de acuerdos entre el gobierno militar y diferentes partidos políticos.

En San Juan, el interlocutor de este acuerdo fue el Partido Bloquista, que tenía una historia de pactos con gobiernos militares, tanto que en 1973 había colocado a su líder, Leopoldo Bravo, como candidato a vicepresidente en la "Alianza Republicana Federal", ${ }^{12}$ la fórmula electoral que propugnaba el continuismo militar de la autodenominada Revolución Argentina (años 1966-1973). Esta cercanía del Partido Bloquista con la corporación militar habría de acentuarse durante la feroz dictadura que gobernó el país entre 1976 y 1983. En tal periodo Bravo fue embajador en la Unión Soviética, en Italia y, cuando ya el proceso electoral era inevitable, Gobernador de facto en el año 1982. 
Con esta posición de privilegio, el bloquismo revalidó su supremacía electoral provincial en ocasión de la reinstauración de las instituciones constitucionales de 1983. Esta preeminencia se extiende a duras penas al segundo periodo gubernamental (19871991), en donde debió recurrir a un candidato extrapartidario y a una serie de recursos de último momento para poder sostenerse en el poder. ${ }^{13}$

Al respecto, es necesario hacer notar que tal supremacía siempre estuvo basada en un escenario electoral que, a diferencia de lo que ocurre en la mayoría de las provincias argentinas, no se caracterizaba por ser fuertemente bipartidista. Es de destacar que en las elecciones realizadas durante las décadas de 1980 y 1990 pudo constatarse en San Juan una importante presencia de varias fuerzas provinciales y municipales, además de los partidos nacionales con presencia en todo las jurisdicciones (la UCR y el PJ).

Manteniéndose ese rasgo de pluralidad, en las elecciones para gobernador de 1991 hubo un cambio del escenario electoral. En efecto, mientras que 1983 y 1987 el bloquismo se había impuesto a partir de un discurso provincialista que apostaba a la división del voto opositor entre la UCR y el PJ, en dicha elección la aparición de otro partido regional -la "Cruzada Renovadora"- dividió al electorado a la vez que se redujo sustancialmente la perfomance electoral de la UCR. Los resultados finales mostraron un virtual empate técnico en el 30\% de los votos entre tres fuerzas electorales: la Cruzada Renovadora, el Partido Bloquista y el Partido Justicialista. Este último es quien finalmente ganó las elecciones en lo que un observador consideró "un recuento para el infarto", accediendo al cargo de Gobernador Jorge Escobar, un empresario sin antecedentes políticos.

\subsection{Hacia el estallido}

La llegada al gobierno del Lic. Jorge Escobar (diciembre de 1991) provocó una moderada expectativa. El discurso de campaña hablaba de un proceso que venía a renovar ciertas prácticas políticas, como así también a terminar con un liderazgo -el del Partido Bloquista y de Leopoldo Bravo- al que se catalogaba de anquilosado.

Sin embargo, su posición era débil. Había ganado por un margen muy estrecho de votos, y debía enfrentarse a la poderosa maquinaria del partido tradicionalmente dominante. Por otro lado, a poco de comenzar el gobierno quedó claro que el Vicegobernador manejaba una parte sustancial de la relación con el Partido Justicialista. Esta situación era particularmente crítica en el parlamento provincial, en donde los pocos diputados del PJ no respondían a Escobar. Por último, en sus primeros pasos el novato gobernador cometió una serie de errores -que, por ejemplo, pusieron a la luz graves hechos de corrupción- que terminan provocando la caída de su gobierno por juicio político a un año de su asunción (diciembre de 1992). ${ }^{14}$ 
Si el gobierno de Escobar era débil, el de su sucesor -el hasta ese entonces Vice Gobernador Juan Carlos Rojas- lo fue más, ya que a la baja proporción de diputados oficialistas en el parlamento provincial se agregaban problemas derivados de una popularidad limitada y de una legitimidad que rápidamente fue puesta en duda por amplios sectores de la sociedad provincial. Es que fue dificil perdonarle que, desde su cargo de vicegobernador, participara de la operación de destitución del gobierno, lo que quedó al descubierto cuando los diputados que le respondían aportaron los votos imprescindibles para la destitución del primer mandatario provincial. Se produjo así una situación en donde Escobar ganó popularidad como "víctima" de una maniobra, mientras Rojas como "victimario" no pudo remontar la situación planteada, a pesar del extraordinario incremento del gasto público aplicado a un sinnúmero de acciones, muchas de ellas muy importantes y muy positivas para la provincia.

Escobar dio el primer paso de su retorno al poder cuando triunfó en los comicios del 3 de octubre de 1993 (elección de legisladores nacionales), a pesar de presentarse por fuera del Partido Justicialista y de enfrentar abiertamente al gobierno provincial. La situación se repitió en las elecciones de convencionales constituyentes nacionales (10 de abril de 1994), logrando en esa ocasión un margen aún mayor sobre los otros partidos. El resonante triunfo tuvo un valor especial porque Escobar duplicó los votos de Rojas, que con el $18 \%$ de los votos apenas pudo arañar el tercer puesto.

La debilidad del gobernador Rojas lo empujó a un desesperado rush por consolidar el apoyo de la estructura justicialista, de los intendentes municipales y de los partidos de la oposición que veían que la suerte del gobernador estaba prácticamente echada. En este intento incrementó de manera ostensible el gasto público al promover, entre otras cosas, el ingreso de aproximadamente 7.000 nuevos empleados al estado; el incremento del gasto llegó a generar un déficit del orden del 40\% respecto de los ingresos.

Hacia el último trimestre de 1994, cuando los primeros embates del "efecto tequila" de la crisis mexicana produjeron un derrumbe de los ingresos provinciales, la situación de las cuentas fiscales era ya insostenible. Las dificultades para pagar salarios hacían que el malestar general, que hasta entonces sólo se había expresado a través del voto, se tradujera en importantes movilizaciones. Ello fue así porque, como vimos, la amplia incidencia del estado en la vida económica en las provincias periféricas hace que su retracción provoque un generalizado corte en la cadena de pagos.

La baja popularidad, las movilizaciones populares y el aislamiento nacional (el ministro de Economía Domingo Cavallo calificó al gobierno provincial como "un desastre", y el diputado justicialista César Arias, en representación del Consejo Nacional del PJ, estimó que "la situación era próxima a lo crítico" (Interdiarios 21 y 26/12/94), hacían prever una pronta salida de Juan Carlos Rojas del poder. La situación se definió a partir 
de un fallo de la Corte Suprema de Justicia sanjuanina, que consideró nulo el juicio político a Jorge Escobar y lo repuso en el gobierno a fines de diciembre de 1994, dos años después de su caída.

Con el regreso de Escobar al Gobierno, se observan dos novedades:

- La amplia apoyatura que consigue el nuevo gobierno de parte del Estado Nacional. En la semana en que retoma el cargo Escobar es recibido por el presidente Carlos Menem, el Ministro del Interior Carlos Ruckauf, el Secretario General de la Presidencia Eduardo Bauzá y el Ministro Cavallo quien, además, le envía una partida extraordinaria de $\$ 10$ millones para poder hacer frente a los sueldos de diciembre.

- El alineamiento con el ajuste promovido por la Nación. En su asunción, Escobar advierte que habrá "una cirugía mayor... al estilo de la practicada en la intervención federal a Santiago del Estero" (Interdiarios, 26/12/1994 y 28/12/1994). Y así fue, en efecto: un agudo ajuste fiscal, tal vez el más duro llevado a cabo por provincia alguna en esa etapa. Para dar una idea de su profundidad, digamos el gasto en personal se redujo en casi un 30\% (pasó de más de \$ 437 millones en 1994 a \$ 317 millones en 1996).

\subsection{Técnicos y políticos}

El plan estratégico del ajuste, y la gestión de sus contenidos más álgidos, fue llevado a cabo por una serie de cuadros profesionales agrupados en el Ministerio de Economía y la Jefatura de Gabinete de la Provincia que, a despecho de ser originarios de San Juan, llegaban desde Buenos Aires. Estos funcionarios se mostraban abiertamente como aliados políticos e ideológicos del Ministro de Economía de la Nación (Domingo Cavallo) y de la necesidad de llevar adelante políticas neoliberales. En el mundillo de la política provincial estos funcionarios fueron conocidos como los "técnicos".

Frente a este segmento estaban los "políticos", ${ }^{15}$ una serie de cuadros históricos del PJ que habían acompañado a Escobar en su amargo retiro post destitución, y que conformaban los principales puentes del gobernador hacia el partido. Este sector representaba una expresión típica de las seccionales provinciales del PJ, en donde se mezcla la apelación a las clases populares, la impronta católica y una concepción cultural conservadora. Más allá del pragmatismo que la coyuntura obligaba a la política provincial -haciendo que sus posicionamientos variaran tras el objetivo central de acumular crecientes espacios de poder- los políticos, como ocurría en el resto del país, no se sentían del todo cómodos con las políticas de ajuste estructural (Jozami, 2004: 41 y Levitsky, 2002: 19).

Era claro que el enfrentamiento entre ambos bandos se desarrolló en función de una cruda lucha por el poder entre dos grupos bastante consolidados que contaba con im- 
portantes lealtades internas. Pero esta disputa estaba acicateada por visiones contrapuestas: la formación generalmente posgraduada y una visión cosmopolita y moderna de los derechos civiles en los cultores del ajuste estructural era el anverso del tradicionalismo folclórico, la religiosidad y el paternalismo de los cuadros peronistas.

Las policy makers neoliberales estaban imbuidos de una enorme confianza en el futuro, la misma que mostraban sus colegas de todo el mundo a partir de la caída de la Unión Soviética. Manejaban una serie de herramientas -que conformaban un todo bastante consistente y sofisticado, pero también cerrado y un tanto esquemático- con el cual hacer análisis, prospectiva e intervención sobre la realidad que les tocaba enfrentar. A partir del apoyo de poderosas oficinas nacionales y de los organismos multilaterales de crédito, como así también de los resultados electorales -sostenían, y los medios del establecimiento lo convalidaban, que las elecciones se ganaban proponiendo profundizar el ajuste- consideraban que estaban llamados a ser los nuevos hombres fuertes de la política argentina.

Estos cuadros hacían gala de un progresismo y anti clericalismo que los diferenciaba de la histórico liderazgo bloquista y que, además, los acercaba a la numéricamente pequeña pero influyente nueva clase media que estaba surgiendo al amparo de la convertibilidad. Como ellas, miraban con desprecio las prácticas clientelares y los arreglos prebendarios que eran fórmula clásica de la política provincial, a las que se dedicaron a destruir con fervor. Para su sorpresa, los ciudadanos "liberados" de las redes de clientela no se convertían en pujantes micro empresarios sino en una masa anómica que los enfrentaría con violencia y que en poco tiempo comenzaría a deteriorar los índices de seguridad provincial. No era que no se dieran cuenta de lo que ocurría... pero ellos consideraban que sólo era cuestión de esperar a que el mercado hiciera su trabajo y cambiara una mentalidad que, según su visión, estaba deformada por décadas de estatismo. Entonces ahí sí, la provincia despegaría inexorablemente.

Los cuadros justicialistas se quejaban de que luego de esperar décadas para llegar al gobierno provincial tuvieran que compartirlo con un gobernador que no tenía experiencia militante y con una serie de recién llegados que "no eran peronistas", no habían sufrido cárcel y persecuciones durante la dictadura, ni habían tenido que pasar por las mortificantes derrotas que les había infligido el bloquismo.Veían con profunda desconfianza a estos foráneos que no respetaban las tradiciones provinciales, tenían un discurso incomprensible con recurrentes giros en inglés, y defendían políticas que amenazaban históricas redes de construcción política a partir de eliminar, limitar o simplemente transparentar los opacos subsidios y exenciones impositivas y de cánones que ostentaban el grueso de las organizaciones de la sociedad civil.

Justo es reconocer que la ruptura de estas redes en muchos casos desestructuraba reglas opacas e injustas que sostenían jerarquías basadas en la tradición. Por ejemplo, las 
políticas de desregulación que limitaban el poder de los colegios profesionales que sostenían el poder de estudios y buffetes cuyo único elemento diferencial era el apellido aristocrático de sus miembros. La defensa a ultranza de los múltiples canales capilares por donde circulaban información, favores y tráfico de influencias -los citados colegios profesionales, clubes, parroquias católicas, asociaciones varias, vecinales, sindicatos, etc.se originaba no sólo en el imaginario comunitario y tradicionalista, sino, sobre todo, en que se trataba del espacio desde donde los "políticos” desplegaban su práctica cotidiana.

Con meridiana claridad un protagonista de aquellas jornadas describe cómo este mecanismo había llegado hasta el lenguaje: "Otro término con el que se sublimaba el clientelismo era el de "solución política". Por ejemplo, cuando un cadete de la escuela de policía no podía entrar porque no había aprobado el examen, entonces se pedía una solución política. Pero no era "política" entendiendo como la articulación del poder o del interés general, era pasar por encima de lo que decían las normas. La solución política era entendida como buscar la solución por la vía de la excepción" (d: 91). Vale agregar, que una solución "técnica” implicaba dejar sin efecto un subsidio o una ayuda, seguramente opaco y poco eficiente, pero que en el contexto de ajuste implicaba el cierre de una empresa, la pérdida de trabajo de un jefe familiar, el fin de la distribución de bienes y servicios a población carenciada, etc. La etapa reconstructiva vendría después, de la mano del automatismo de mercado, por lo que no le concernía al estado.

Los políticos se sentían un poco intimidados frente a la autoconfianza y los pergaminos académicos que mostraban los técnicos y tampoco contaban con herramental teórico para enfrentarlos, ya que las históricas ideas justicialistas eran puestas en ridículo por sus contendores (la frase típica de la época era "te quedaste en el 45", haciendo alusión a la fecha de la asunción del primer gobierno peronista). Esta situación psicológica estaba vinculada también a que el justicialismo local no tenía, como en otras provincias, una larga experiencia de gestión, por lo que no se sentía del todo seguro de poder manejar "su" estado (y allí estaba la fallida experiencia de Juan Carlos Rojas que mostraba que todo podía terminar muy mal). Más allá de esto, desconfiaban profundamente del futuro "derrame" que, según pregonaban los técnicos, llegaría a todos en algún momento y en las distintas reuniones internas les pasaban factura acerca de los terribles efectos sociales que estaba generando el ajuste. Por supuesto los técnicos se defendían con suficiencia, dibujando curvas y sacando a la luz datos acerca de lo bien que iba todo... pero su discurso, independientemente de lo apropiado que fuera para caracterizar la realidad, era inentendible para el ciudadano común.

Se sucedían así escaramuzas, en donde los técnicos atacaban desde el desarrollo de programas y acciones que, sostenidas potentemente por buena parte de los medios de comunicación, tendían a desestructurar las redes que vinculaban -por medio del favores y privilegios- a los políticos con la sociedad civil. 
Una dimensión importante de estas redes era su influencia sobre distintos ámbitos de gestión -jurídicos, contables, presupuestarios, logística general, etc. - que hacían que toda medida que los técnicos quisieran implementar fuera una odisea. De esta manera, acciones rutinarias tales como el nombramiento de agentes de mínima categoría, funcionamiento de procesos internos, aprobaciones presupuestarias o jurídicas, promulgación de normativa, utilización de la red informática, etc. sólo avanzaban como excepción y al calor de las negociaciones en el micro y macro escenario político social. Este era el escenario que todos daban por supuesto: la iniciativa de los técnicos, las redes capilares utilizadas de forma defensiva por los políticos. Para los técnicos era cuestión de tiempo para que el viento de la historia se llevara a los políticos; para éstos había que resistir y negociar en la espera de un cambio de época. Para sorpresa de todos, la definición de esta batalla se iba a producir en el lugar menos esperado: la calle.

\subsection{El sanjuanazo ${ }^{16}$}

Los "políticos" tenía lazos con el Frente Social, un grupo de organizaciones liderado por sindicatos y colegios profesionales ligados a la Administración Pública que se había organizado en las jornadas de lucha de fines de 1994 contra el en ese momento Gobernador Rojas. La del Frente Social había sido una experiencia novedosa en una provincia en donde hacía largos años que no se desarrollaban conflictos político-sociales sostenidos por una participación popular determinante.

Con el lanzamiento del plan de ajuste de Escobar, se reanuda la actividad del Frente Social. Si bien en un principio sus disidencias internas lo debilitan -el sindicalismo mayoritariamente peronista no quería enfrentarse abiertamente a un gobernador justicialista de llegada directa al presidente Menem- la red organizativa que lo sostenía estaba destinada a ocupar un lugar crucial en los hechos que iban a suceder. Aunque el gobernador Escobar aparecía por encima de las tensiones que cotidianamente ocurrían entre técnicos y políticos hasta las elecciones de mayo de 1995 -que significaron, paralelamente, la reelección de Menem y de Escobar- el gobernador apuntaló fundamentalmente al sector que llevaba adelante el ajuste estructural.

Como vimos en la sección 2.2. y el gráfico, a partir de esa fecha se abrió un periodo de cambios en la relación con la Nación que implicó un paulatino alejamiento del Ministro Cavallo, que había caído en desgracia, y un estrechamiento de las relaciones con otras figuras en alza. El objetivo de estos cambios era, claramente, mantenerse como interlocutor privilegiado del Gobierno Central.

Pero no nos adelantemos a los hechos. Volvamos a los primeros meses del año 1995, cuando las primeras fases del despliegue del programa de ajuste parecían no hacer mella sobre la gobernabilidad provincial. 
El primer gran test en este sentido fueron las elecciones de todas las autoridades electivas provinciales ${ }^{17}$ el 14 de mayo de 1995, en donde Escobar obtuvo un abrumador triunfo para los estándares sanjuaninos acostumbrados a elecciones relativamente parejas. Haciendo una síntesis extrema, pude decirse que el electorado reeligió al gobernador para que, ajuste mediante, garantizara la continuidad del pago de salarios a los empleados públicos y la cadena general de pagos en la provincia, en un fenómeno en alguna medida paralelo al que en ese momento se daba con las elecciones presidenciales. ${ }^{18}$

Los resultados indicaban, además, que Escobar había logrado alinear a todo el PJ en derredor de su candidatura; y que en los próximos cuatro años no tendría amenazas desde el interior del partido oficial. Asimismo, pareció implicar la derrota final del Frente Social, que parecía que iba a deshilvanarse cada vez más con el retiro del ala sindical, ahora disciplinada hacia el indiscutido nuevo liderazgo del peronismo.

En resumen, hacia principios de junio el gobierno parecía tener la situación bajo control. Había logrado un rotundo triunfo electoral en medio de un ajuste muy violento, reagrupando a todo el PJ detrás de sí. Por otro lado su hábil realineamiento con la Nación lo mantenía como un interlocutor privilegiado del poder central, la protesta social aparecía vencida a partir de los resultados de los comicios y la situación fiscal, si bien planteaba varias batallas pendientes, iba mejorando paulatinamente.

Este escenario casi idílico para el gobierno iba a cambiar bruscamente en menos de dos meses, hacia fines de julio.

Como telón de fondo que potenció la debilidad del gobierno de Juan Carlos Rojas y condicionó el desarrollo del ajuste llevado a cabo por Escobar, estaba la llamada "crisis del tequila", que hizo que casi todas las provincias sufrieran una aguda crisis fiscal. El mes de julio fue tal vez uno de los más críticos de todo el periodo; además de los procesos que veremos en detalle referidos a la Provincia de San Juan, hubo programas de ajuste draconianos, tumultos o asistencias de urgencia en Chaco, Córdoba, Corrientes, Entre Ríos, La Rioja, Catamarca, Misiones y Río Negro. ${ }^{19}$

En este escenario, y con la legitimidad dada por el triunfo electoral, el ala técnica del gobierno consideró que estaban dadas las condiciones para desplegar una serie de medidas tendientes a lograr el definitivo arreglo de las cuentas fiscales de la provincia. Adicionalmente, se consideraba que con estas medidas se podría -en ocasión de la recuperación económica postequila- generar un excedente con el cual dejar expedito el camino para el desarrollo de un programa de reconversión y modernización de la base productiva. Tras esta perspectiva, se logra que la legislatura provincial apruebe a principios de julio la declaración de "Emergencia económica, financiera, administrativa y previsional" que autorizaba la rebaja salarial, la emisión de bonos, la eliminación de organismos del 
Estado, el lanzamiento de un plan de retiros voluntarios y la transferencia de la Caja de Jubilaciones al Estado Nacional. El lanzamiento de estas medidas se realizó a pesar del voto en contra de toda la oposición y del antagonismo de sindicatos y de colegios profesionales ligados al Estado. Pero luego de obtener la aprobación de la ley, el ejecutivo no la transformó inmediatamente en medidas concretas ¿Dudas ante la posible reacción, un impasse para resolver la puja interna? Algunos de los protagonistas de la historia dan una razón mucho más pueril: la dificultad para gestionar una serie de medidas complejas con una administración pública que hacía meses que no funcionaba. La cuestión es que, como en casi todas las jurisdicciones, no había recursos como para pagar los sueldos -con ajuste o sin ajuste- por lo que el ambiente comenzó a enrarecerse. El 13 de julio manifestantes del Frente Social apedrearon el Ministerio de Economía de la provincia en reclamo del pago de sueldos y aguinaldo.

Con el correr de los días la tensión fue creciendo, hasta que el 24 de julio, finalmente, se hizo efectivo el elemento más crítico de la ley de Emergencia Económica: se estableció que habría una reducción de los salarios mayores a $\$ 400$; en un $30 \%$ para los docentes, en un $20 \%$ para el resto del personal. Paralelamente, se anunció que los sueldos de junio y el medio aguinaldo serían pagados en cuotas a partir de septiembre.

Con esta medida, el sector partidario del ajuste pensaba terminar definitivamente con el déficit, tal como "se propuso en la campaña electoral y esto fue lo que la gente de la provincia votó masivamente”. Desde este espacio se sostenía que Escobar había iniciado su gobierno con un déficit de \$23 millones por mes, el que con un gran esfuerzo había sido reducido a $\$ 10$ millones, pero era necesario hacer todavía más. Se sostenía que una vez desplegadas estas medidas se terminaría con el déficit y con la penuria de conseguir "pagar los sueldos mes a mes". Se argumentaba que el gobierno se enfrentaba a un dilema: “ ...o despedíamos a 9 mil trabajadores del estado... o disminuíamos un poco el salario" (Interdiarios, 27/07/95).

Funcionarios del gobierno comentaron que pensaron en sincronizar el lanzamiento de estas medidas con el pago de una parte de los salarios atrasados, para lo cual se recibió asistencia financiera de la Nación. Sin embargo, al tener que utilizar como vía de ingreso de esos fondos al Banco Provincial -exclusivo agente financiero de la provincia-, ocurrió que el Banco absorbió esos fondos para superar su propia crisis financiera. En el momento más delicado de la crisis el Banco Provincial le debía u\$s 63 millones al Estado Provincial, el equivalente a dos meses de gasto salarial provincial (Página 12, 30/07/95a).

¿Por qué se lanzaron las medidas en ese momento? Los entrevistados dieron varias respuestas. Por un lado, porque era la condición que ponía el Ministerio de Economía de la Nación para dar financiamiento extraordinario. Pero también, el ala técnica especulaba con que el escenario extrema penuria fiscal y tensión social jugaba a su favor 
en el disciplinamiento del ala política. No fue así. La confluencia de medidas de ajuste, atraso salarial y baja cobertura política desató una ola de disturbios como nunca antes se había visto.

La protesta de los sindicatos nucleados en el Frente Social comenzó en la noche del martes 25 , con la ocupación de los ministerios sanjuaninos. El miércoles 26 de julio se produjeron los incidentes más graves, alcanzando su cenit cuando manifestantes del Frente Social, liderados por el Secretario General del sindicato de trabajadores de sanidad (ATSA), ocuparon la sede del Ministerio de Desarrollo Humano (ex Acción Social), rompiendo muebles y vidrios e intentando incendiar el edificio. Los hechos incluyeron destrozos e incendio de vehículos, roturas de vidrieras, saqueos de comercios y choques con efectivos de la policía provincial. Un grupo de manifestantes rompió a piedrazos las vidrieras de la concesionaria Ford, propiedad de la familia del gobernador Jorge Escobar, y el edificio 9 de Julio, sede del Ministerio de Economía, se mantuvo tomado durante todo el día por militantes de ATE, el sindicato de trabajadores estatales. El saldo de los enfrentamientos fue una veintena de heridos y una decena de detenidos. Por la noche, el gobierno provincial debió pedir ayuda a la Gendarmería y a la Policía Federal en prevención de que hechos similares pudieran repetirse al día siguiente (Interdiarios, 27/07/95)

Tras los disturbios se lanzó un paro general apoyado por todas las centrales del sindicalismo nacional -Confederación General del Trabajo (CGT), Movimiento de Trabajadores Argentinas (MTA) y Central de Trabajadores Argentinos (CTA) - y los gremios estatales, el que, combinado con un asueto declarado de apuro para la administración pública y el Poder Judicial, tuvo un acatamiento total. El viernes 28 unos tres mil manifestantes se concentraron frente a la catedral, sin que se produjeran incidentes y Héctor Sánchez de la Asociación de Trabajadores del Estado (ATE), una de las caras visibles del sanjuanazo, anunciaba para la semana siguiente un plan de lucha mientras afirmaba: "para la otra semana, estamos seguros, esto se convertirá en un estallido de tipo nacional" (Interdiarios, 31/07/95 y Página 12,30/07/95b)

En ese momento, empezaba a ser visible en el gobierno la puja entre quienes querían negociar una salida decorosa de la tensa situación y quienes promovían una rendición completa. Esta controversia se reflejaba en el propio gobierno nacional, como recuerda un funcionario provincial que tenía línea directa con la Nación: "mientras (el Ministerio de) Economía nos decía que soportáramos el embate, que ellos nos hacían el aguante, (el Ministerio del) Interior nos conminaba a que arregláramos a como diera lugar".

En este escenario, el ala política tomó la iniciativa. La Legislatura provincial dio marcha atrás y sancionó la ley $\mathrm{N}^{\circ} 6.619$ que prohibió la reducción salarial. La norma fue aprobada con los 22 votos de la oposición (Cruzada Renovadora, Partido Bloquista y UCR) y, notoriamente, 14 del oficialismo (Microsemanaraio, 1995b). 
El Vicegobernador Rogelio Cerdera -la cara más visible de esta política- expresó: “es hora de que nos sentemos todos los que somos responsables, esto es el gobierno, dirigencia sindical, dirigencia empresaria, la iglesia... para asegurar una convivencia armónica en esta provincia" (Interdiarios, 27/07/95). No es necesario hacer muchos esfuerzos para notar el cambio de actitud en comparación con el decisionismo que caracterizó el lanzamiento de la ley de emergencia en particular y todo el periodo en general.

Finalmente, tras una nueva huelga general realizada con gran acatamiento el jueves 3 de agosto, la Gobernación dejó sin efecto descuento alguno. Emblemáticamente, Alfredo Duarte, Secretario General de ATSA, que apareciera en las filmaciones del 26 de julio en el incendio del Ministerio de Desarrollo Social, ${ }^{20}$ fue quien confirmó que se había llegado a un entendimiento y que la situación se había descomprimido (Interdiarios, 04/08/95). Sólo continuaron con su protesta los empleados y obreros sanjuaninos agrupados en ATE, quienes rechazaron la oferta del gobierno. Pero el estallido nacional no se produjo, agosto fue el mes en donde comenzó a mejorar el escenario fiscal y la lucha provincial comenzó a diluirse a favor del apoyo incondicional de sindicalismo ortodoxo al gobierno, el archivo de los planes de reducción salarial y la renuncia o desplazamiento de los lugares de poder de los "técnicos".

\section{Consecuencias del sanjuanazo}

La primera consecuencia que salta a la vista del sanjuanazo es el cambio en el equilibrio interno del gobierno de Escobar, que pasó a estar hegemonizado por el ala política. A pocos meses de los hechos que relatamos, la mayoría de quienes habían liderado el ajuste estructural no sólo salieron del gobierno, sino que volvieron a sus ocupaciones en Buenos Aires. Los "políticos", por su parte, se sintieron dueños de la situación y superaron las trabas políticas, sociales y hasta sicológicas que tenían para apropiarse, definitivamente, del Estado Provincial. Sin embargo, y más allá del resultado de la batalla -no se redujeron los sueldos y los técnicos dejaron el gobierno- la dirección de fondo de las políticas estatales y el alineamiento con el gobierno nacional no cambió.

Volvamos sobre las definiciones ya hechas: así como los técnicos representaban la idea de llevar a fondo el programa del ajuste estructural, los políticos expresaban la descomposición de una sociedad que no encontraba un proyecto para salir de la debacle de las economías regionales, y en consecuencia sólo podían llevar adelante una política defensiva. En tal condición, el recambio significó pasar de estar a la vanguardia de las políticas de ajuste a formar parte de un moderado pelotón que si bien no las lideraba tampoco se oponía a las políticas neoliberales que se inducían desde el nivel nacional. Esto nos lleva a una segunda consecuencia que puede enlazarse a la remanida imagen del vaso medio lleno o medio vacío: junto con la rebaja salarial, se archivaron para siempre proyectos como los de las “escuelas charter", el arancelamiento hospitalario, la descentralización a 
municipios de servicios esenciales; más allá de esto, los “políticos” ni siquiera imaginaron que se podría cambiar la matriz económica y fiscal en curso.

En este plano relativamente gris, consistente además por el recambio a nivel nacional, del hiperactivo Ministro Cavallo por el cultor del "piloto automático" Roque Fernández, el gobierno de Escobar transcurrió su periodo con una relativa holgura fiscal -lo que marca hasta dónde había avanzado el ajuste de los técnicos- que fue haciendo quedar en el recuerdo al sanjuanazo. Sería necesaria otra megacrisis -la de 2001/2- para que cambiara el tono del accionar estatal.

\subsection{El Sanjuanzo y el nuevo papel de la política provincial}

Siempre quedó la duda acerca del papel de sindicatos que respondían al PJ en los hechos ocurridos. Sin pretender explicar la situación a través de teorías conspirativas, resulta bastante claro que tuvieron "piedra libre" por parte del ala política para presionar al gobierno en pos del desgaste del ala técnica. Sin embargo, cuando la situación se les escapó de las manos rápidamente acordaron una salida para descomprimir un conflicto que había superado por mucho los límites previstos. Más allá de este vaivén, toda la sociedad política tomó nota de la importancia de la movilización popular, elemento que previo al sanjuanazo se consideraba de poca eficacia en una sociedad que se veía a sí misma como mansa y pueblerina.

También parece cierto que hubo una mala evaluación de la situación por parte del ala técnica, al suponer que su protagonismo en el triunfo electoral le daba la oportunidad de profundizar su proyecto político, como así también hacerle pagar a sus contendientes del ala política el costo del atraso en el pago de salarios. El carácter tecnocrático de los funcionarios que no habían estado viviendo en la provincia y la baja inserción en las organizaciones populares los llevó a realizar un cálculo errado acerca de las consecuencias de profundizar las medidas de restricción del gasto.

En todo caso, lo ocurrido refiere a un clásico del análisis político: a partir de contradicciones secundarias irrumpen las tendencias principales; en este caso, las tensiones entre técnicos y políticos abrieron una brecha por donde se expresó toda la tensión que, en el marco del tequila, estaba generando el ajuste estructural.

Analizados los hechos desde un enfoque macro, el sanjuanazo puso a la luz las potencialidades y limitaciones del nuevo esquema sociopolítico que había comenzado a construirse a partir de mediados de la década de 1970.

Como se ha explicado, las transformaciones iniciadas por tal época implicaron cambios en el pacto social que sostenía el sistema político provincial; en la etapa anterior, el gobierno provincial tenía como principal tarea sostener la economía regional, en la etapa 
que siguió, su accionar pasó a centrarse en la obtención de recursos que transfería el Estado Nacional cuya asignación entre actores sociales y políticos provinciales, configuraba el principal elemento de la gobernabilidad provincial.

Ahora bien, la crisis fiscal a partir del efecto tequila develó con toda crudeza los límites del gobierno provincial; en ocasión de situaciones en donde el ciclo económico nacional le reduce los recursos que recibe, debe producir un ajuste que ataca directamente a su principal base de sustentación. En la Administración Pública tiene límites infranqueables en virtud del múltiple efecto que esta política tiene sobre todos los estamentos de la vida provincial.

Un punto importante relacionado con este tema y que salió a la luz con el sanjuanazo, fue el drástico acotamiento en las posibilidades de exportar el conflicto político hacia el ámbito nacional, tal como ocurría en la etapa anterior. Podemos decir que Escobar no podía hacerlo porque basaba buena parte de su fortaleza en mostrarse como el mejor aliado del gobierno central. Pero, además, considerando que se había roto el discurso productivista que permitía una apelación al orden nacional -básicamente el que sostenía que el gobierno central estaba fijando reglas lesivas para la vitivinicultura a favor de otros actores regionales- el papel mendicante ${ }^{21}$ que le cabe a la contraparte provincial hacía que fuera más difícil construir un contradiscurso. En suma, en el mismo momento en que la dinámica interna provincial recuperaba conflictividad, se limitaban las herramientas discursivas con que contaba el gobierno para enfrentarla.

Finalmente, pero no menos relevante, señalamos el surgimiento de un nuevo actor en el escenario político provincial. Las movilizaciones de julio de 1995 tuvieron tal importancia que elVicegobernador de la Provincia tuvo que reconocer que se trataba de un fenómeno inédito en San Juan (Interdiarios, 27/07/95). Más allá del papel que desempeñaron los diferentes espacios superestructurales - muchos de ellos primero promoviendo la protesta y luego desalentándola- la amplitud e intensidad de la protesta demostró que las condiciones habían cambiado de manera sustancial. En efecto, el nivel de masividad y combatividad con que se expresó una importante porción de la población provincial, dejó a las claras que había en sociedad regional una reserva latente, lista para expresarse a través de la organización de los sectores populares de la provincia.

\subsection{A modo de conclusión: lo que vino después}

En 1999 Escobar volvió a presentarse como candidato a gobernador, realizando una muy buena elección para los estándares sanjuaninos -superó el 43\% de los votos- pero no alcanzó para derrotar una alianza que reunió a todos los elementos del complejo mosaico electoral provincial (UCR, FREPASO, Cruzada Renovadora, Bloquismo y partidos menores) y llevó como candidato a Alfredo Avelín. A diferencia de lo que era una 
especialidad del bloquismo, el PJ no supo, no quiso o no pudo dividir a la oposición y, sorpresivamente, perdió la gobernación.

Más allá de las limitaciones del nuevo gobierno y del complejo escenario que le tocó vivir, no era difícil prever que la alianza podía ser muy efectiva para obtener votos, pero su heterogeneidad hacia que fuera casi imposible que gobernara.Y así ocurrió, en efecto: la tremenda crisis del 2001, la falta de pericia y una descarnada interna, terminaron generando una pueblada que llevó a la destitución del Gobernador Avelín en 2002: fue el segundo sanjuanazo.

El frente social, que protagonizó el primer sanjuanazo marcó un antes y un después de la participación popular en la provincia. Si en una etapa en donde las fuerzas populares estaban en retirada se alcanzó el impacto que describimos aquí, no era difícil prever el impacto que tendría cuando en todo el país se viviera un auge de masas. En este sentido el Frente Social es el antecedente directo del segundo sanjuanazo y de los grupos piqueteros provinciales.

El discurso del Frente para la Esperanza del gobernador Escobar articulaba elementos del ajuste estructural con un discurso modernizador y de los derechos civiles frente al tradicionalismo bloquista. ${ }^{22}$ Este cruce se fue deconstruyendo durante el periodo de Escobar (1991-1999) hasta construir un nuevo discurso para las clases hegemónicas provinciales en donde se articulaban los contenidos neoliberales con una cosmovisión católica moralista y conservadora. No puede minimizarse el papel del Opus Dei en esta reconfiguración.

Después de más de dos décadas de retorno de la democracia el fracaso de las diferentes propuestas políticas era manifiesto. San Juan, que como parte de la región de Cuyo apareció durante la segunda mitad del siglo XX como una transición entre la Patagonia moderna y el NOA retrasado, se había convertido en una de las provincias más pobres del país.

Hasta que la confluencia de distintos elementos del gobierno nacional con otro gobierno provincial permitió reconstruir un proyecto políticamente viable para la provincia, el cumplimiento de las normas más básicas de elección de gobernantes y la estabilidad institucional pendieron de un hilo. 
${ }^{1}$ Así se denominó a la crisis ocurrida a partir del salvataje que los organismos multilaterales de crédito reali-
zaron del sistema financiero mexicano. Para los países que dependían de los flujos internacionales de crédito,
como la Argentina, la situación se volvió dramática. Durante el año 1995 el PBI de nuestro país descendió más
de un $4 \%$ y se temió por el descontrol de la economía. Finalmente, hacia la segunda mitad de ese año, la crisis de un $4 \%$ y se temió por el descontrol de la economía. Finalmente, hacia la segunda mitad
comenzó a ceder y la economía argentina, a un alto costo social, logró superar la situación

${ }^{2}$ Esta no ha sido la principal veta del análisis de las provincias periféricas en los últimos años; en esto ha sido influyente la perspectiva inaugurada por el clásico trabajo de Guillermo O’Donnel (1993), que nominaba como zonas "marrones" a aquellas en donde las instituciones políticas no tenían un funcionamiento equivalente al que se desplegaba en los países desarrollados. A su saga, y a partir de la preponderancia del análisis institucional, se desplegó una serie de estudios como los de Gervasoni (2009), Behrend (2011), Gibson (2006) que analizan la situación provincial desde el despliegue de las reglas políticas en uso. El presente escrito se inscribe en otra tradición, la que enlaza en sus análisis la política y la estructura socioeconómica partiendo de la perspectiva regional. En este sentido emparenta con las investigaciones de Dargoltz (2006) en Santiago del Estero y Iuorno y Favaro (2007) en la norpatagonia -Río Negro y Neuquén-, entre otros.

${ }^{3}$ En Cao,Vaca y Rubins (2003) analizamos diferentes clasificaciones de provincias, las que muestran diferencias menores entre sí y con la utilizada en el presente trabajo.

${ }^{4}$ Este proceso fue relatado en Cao y Rubins (1998). Los procesos históricos de la provincia pueden seguirse, por ejemplo, en Videla (1962), Illanes (2010), entre otros.

${ }^{5}$ Existe abundante bibliografia sobre las economías regionales y su crisis. Ver por ejemplo Rofman (2000).

${ }^{6}$ Corresponden a los Censos Nacionales Industrial y Económico, respectivamente. En el rubro citado, casi el $50 \%$ de la mano de obra ocupada corresponde al ítem "Elaboración de Vinos".

${ }^{7}$ En este párrafo se toman ideas desarrolladas para otro contexto por Reboratti (1996: 164).

${ }^{8}$ Se utilizan entrevistas realizadas en ocasión de desarrollar el trabajo Cao (2003), cuyo Tomo II transcribe la desgrabaciones completas. Las letras refieren a los diferentes entrevistados y las páginas al citado Tomo II.

${ }^{9}$ En el pico de la crisis -mayo del 2002- la encuesta permanente de hogares consignaba que más del $60 \%$ de la población del Gran San Juan se encontraba por debajo de la línea de pobreza.

${ }^{10}$ Desde las polémicas entre Alberdi y Sarmiento, la organización federal de la Argentina ha estado sujeta a acaloradas y profundas polémicas que se desarrollaron en derredor de argumentos jurídicos, políticos, económicos y geográficos. De la muy abundante bibliografia citamos los clásicos trabajos de Frias (1980) y Agulla (1967). Una aproximación desde diferentes perspectivas que se han tratado en los últimos años puede hacerse desde las compilaciones de Calvo y Abal Medina (2001), Gibson (2004) y las revistas Documentos y Aportes $\mathrm{N}^{\circ}$ 9 (Autores varios, 2007), Revista de Occidente $\mathrm{N}^{\circ} 229$ (Autores varios, 2000) y Contribuciones $\mathrm{N}^{\circ} 4$ (Autores varios, 1993), íntegramente dedicadas al tema. Los patrones de alianza del gobierno central con las provincias periféricas en el contexto de reformas económicas de los 90 han sido desarrollado en Gibson y Calvo (2000) y Cao (2003: 152 y ss).

${ }^{11}$ Este razonamiento se desarrolla en extenso en Cao, 2003

${ }^{12}$ El candidato a presidente fue el Brigadier Ezequiel Martínez. La ARF obtuvo el 3\% de los votos a nivel nacional, pero en San Juan la fórmula a gobernador -integrada por Bazán Agrás / Rodríguez Castro- fue la primer minoría, perdiendo ajustadamente en segunda vuelta frente al FREJULI (Camus/Aguilar).

${ }^{13}$ El bloquismo, hegemónico en los medios, fue publicando encuestas y produciendo hechos de forma tal de evitar polarizar con otra fuerza y dividir el voto opositor entre la UCR y el PJ. Ganó así la elección con el $31 \%$ de los votos frente a un empate del PJ/UCR con $27 \%$ de los sufragios cada uno. El candidato extrapartidario fue Carlos Enrique Gómez Centurión, que había sido gobernador de facto en los años 1972-1973, durante la presidencia de facto del general Agustín Lanusse).

${ }^{14}$ El proceso de destitución de Escobar es relatado, aunque con ciertas inexactitudes, en Rodrigo (2011:3034). Un análisis estructural de la época puede verse en Muro y otros (1999).

${ }^{15}$ En un trabajo realizado en la época en que sucedían los hechos que aquí reseñamps, caracterizamos a los contendientes: "Mientras los técnicos son los vehículos de la reformulación del estado en los términos que se establecen desde el mercado mundial, los políticos son los que buscan que el accionar del estado permita, por la vía clientelar, la reproducción de las fracciones sociales y productivas más expuestas. Ambas soluciones presentan límites: por la crisis de financiación (los políticos) o por explosión social o presión de los grupos de poder (los técnicos)" (Cao y Rubins, 1997: 105). Mantenemos la definición, ajustando el rótulo de los contendientes; hoy diríamos que representaban, respectivamente, el programa del capital financiero internacional y la descomposición de la burguesía local. Sobre técnicos y políticos, sus culturas y formas de entender la política, 
puede verse, además del trabajo citado, las compilaciones de Thwaites Rey y López (2005), Estévez y Ochoa (2006) y de la Revista Nueva Sociedad (Autores varios, 1997).

${ }^{16}$ Se han desarrollado importantes relatos de las puebladas de la periferia que enfrentaron el ajuste. Ver, por ejemplo, los trabajos de Dargoltz (1995) y Farinetti (2000) sobre el santiagueñazo, Benclowicz (2005) sobre el caso Tartagal/Mosconi y el de Costallat (1999) sobre el Caso Cutral Co - Plaza Huincul.

${ }^{17}$ En ese momento se eligió gobernador, legisladores provinciales, intendentes y concejales. A diferencia de lo que ocurre en la mayoría de las provincias, la constitución provincial establece el recambio completo de la legislatura, lo que hizo que Escobar comenzara su nuevo periodo de gobierno con mayoría en la legislatura provincial.

${ }^{18}$ En donde el triunfo de Menem se interpretó como un mandato para salvar la convertibilidad amenazada por el "efecto tequila". Escobar fue reelecto gobernador con casi 20 puntos de ventaja sobre el bloquismo y 25 sobre la Cruzada Renovadora-UCR ( $48 \%$ a $28 \%$ y a $23 \%$ ).

${ }^{19}$ En una reunión de gobernadores en la Casa Rosada el 14 de Julio, Mario Moine, Gobernador de Entre Ríos, dijo con acidez al presidente: "Cavallo tiene que estar contento porque estamos privatizando, bajamos los sueldos, le pasamos los jubilados. Pero en cualquier momento van a tener que mandar cuatro o cinco interventores provinciales, porque el costo político de esto es altísimo para los gobernadores" (Microsemanario, 1995a).

20 "Hemos visto por los canales de televisión local ... al Secretario General del Gremio \{ATSA\}, el Señor Duarte, arengando en la puerta del edificio, mientras se tiraban elementos combustibles adentro del edificio para incentivar el fuego" (Interdiarios, 27/07/95)

${ }^{21}$ Veamos los ejemplos que nuestros informantes comentan al respecto: “... buena parte de nuestra tarea era la de pedir recursos, más bienes... o lo que fuese. Inclusive aunque no hubiera un programa, que venga la plata, que con eso acá nos la íbamos a arreglar" (b: 82/83).Y por supuesto la parte Nacional, funcional a esta actitud "A mí no me gustaba tener la sensación de que uno iba a rapiñar las cosas (...) pero no eran así los códigos, se podía pedir lo que fuera que por ahí te lo daban. Yo he visto a ministros ir puerta por puerta entrando a ver qué es lo que hay, una cosa anárquica (...) Allá te atendía el supremo que te decía 'a vos te voy a dar y a vos no te voy a dar"” (g: 111).

${ }^{22}$ Resulta tentador asimilar esta situación a la que ocurrió en el seno del FREPASO desde los comicios de 1995 en adelante, y que se justificaron en trabajos como los de Palermo y Novaro (1996) o en la compilación hecha por Novaro (2002). Al respecto ver el análisis de Jozami (2004:56 y 57). 


\section{Refencias bibliográfícas}

Agulla, Juan Carlos (1967) Federalismo y Centralismo. Ediciones Libera - Buenos Aires

Autores varios (1994) Contribuciones - Revista de la Fundación Konrad Adenauer de la Argentina, No. 4.

Autores varios (1997) Nueva Sociedad No 152.

Autores varios (2007) Documentos y Aportes, Revista de la Universidad Nacional del Litoral, No. 9.

Behrend, Jacqueline (2011) "The Unevenness of Democracy at the Subnational Level: Provincial Closed Games in Argentina”. Latin American Research Review 46 (1) 1:150-176.

Benclowicz, José Daniel (2005) "Notas sobre la formación y el desarrollo del movimiento de trabajadores desocupados de Tartagal-Mosconi (provincia de Salta, Argentina)" Informe final del concurso: Partidos, movimientos y alternativas políticas en América Latina y el Caribe. Programa Regional de Becas CLACSO, Buenos Aires.

Caetano, Gerardo (Compilador) (2006) Sujetos sociales y nuevas formas de protesta en la historia reciente de América Latina. Buenos Aires, CLACSO.

Calvo, Ernesto y Abal Medina, Juan Manuel (2001) El federalismo electoral argentino: sobrerrepresentación, reforma política y gobierno dividido en la Argentina. Buenos Aires, Eudeba/INAP.

Cao, Horacio (2003) La especificidad del Estado y la Administración Pública en las Provincias del área periférica de la República Argentina .Tesis de Doctorado, Comisión de Doctorado. Facultad de Ciencias Económicas, Universidad de Buenos Aires.

Cao, Horacio y Rubins, Roxana (1996) “Economías regionales y crisis económica”. Realidad Económica 141:11-18.

Cao, Horacio y Rubins, Roxana (1998) “Técnicos y Políticos: Un clásico en la puja por el manejo de los Estados Provinciales”, en Gustavo Blutman, comp., Cuaderno No. 3, Serie de Investigación en Administración Pública. Co-edición oficina de Publicaciones CBC - IIA - CIAP - FCE - UBA.

Cao, Horacio y Rubins, Roxana (1998) “La cuestión regional y la conformación del Estado - Nación en la Argentina”. Cuaderno de Investigación CEPAS No 2. 
Cao, Horacio; Vaca, Josefina y Rubins, Roxana (2003) “Clasificaciones y Agrupamientos de Provincias y Territorios de la República Argentina - Cuaderno de Investigación CEPAS Nº 14.

Costallat, Karina (1999) Efectos de las privatizaciones y la relación Estado-Sociedad en la instancia Provincial y Local: el caso Cutral Co-Plaza Huincul. INAP, Dirección Nacional de Estudios y Documentación.

Dargoltz, Raúl (1995) El Santiagueñazo. Gestación y Crónica de una pueblada argentina. Santiago del Estero: El Despertador Ediciones.

Dargoltz, Raúl; Cao, Horacio y Gerez, Oscar (2006) El nuevo Santiagueñazo: cambio político y régimen caudillista. Buenos Aires: Biblios.

Estévez, Alejandro y Ochoa Henríquez, Haydeé (2006) El poder de los expertos. Para comprender la tecnocracia. Maracaibo: Centro de Estudios de la Empresa, Facultad de Ciencias Económicas y Sociales de la Universidad del Zulia.

Farinetti, Marina (2002). Los significados de un estallido social: Santiago del Estero en 1993. Tesis de Maestría, Universidad de Buenos Aires.

Favaro, Orietta y Iuorno, Graciela (2007) “Neuquinos y rionegrinos ¿cautivos o cautivados por los sistemas políticos locales?". Periferias Revista de Ciencias Sociales_No 15: 31-48.

Frías, Pedro J. (1980) Introducción al Derecho Público Provincial. Buenos Aires, Depalma.

Gervasoni, Carlos (2009) "Democracia y autoritarismo en las Provincias Argentinas" en Revista Aportes N 27: 23-36.

Gibson, Edward, ed. (2004) Federalism and Democracy in Latin America. Baltimore, Md.: The Johns Hopkins University Press.

Gibson, Edward (2006) “Autoritarismo subnacional: estrategias territoriales de control político en regímenes democráticos" Revista Desafíos (Centro de Estudios Políticos e Internacionales (CEPI), de las Facultades de Ciencia Política y Gobierno y de Relaciones Internacionales de la Universidad del Rosario) $N^{\circ} 14: 35-52$.

Gibson, Edward y Calvo, Ernesto (2000) “Federalism and Low-Maintenance Constituencies: Territorial Dimensions of Economic Reform in Argentina," Studies in Comparative International Development, vol. 35 (3) 32-55. 
Illanes, Daniel (2010) Historia de San Juan. Desde los orígenes hasta la actualidad. San Juan, Ediciones del laberinto.

INV - Instituto Nacional de Vitivinicultura (2002) Síntesis Básica de Estadística Vitivinícola Argentina. Datos Definitivos. Instituto Nacional de Vitivinicultura, Mendoza, Argentina.

Jozami, Eduardo (2004) Final sin gloria. Buenos Aires, Editorial Biblos.

Levitsky, Steven (2002) Una desorganización organizada: organización informal y persistencia de estructuras partidarias locales en el peronismo argentino. Bernal, Pcia. De Buenos Aires: Universidad Nacional de Quilmes.

Muro, María; Grillo, Mirta; Giugni, Alicia y Bocelli, Nora (1999) El modelo de desarrollo. Algunos efectos sobre la sociedad sanjuanina - IISE/GEIS - FACSO/UNSJ - San Juan, Argentina.

Novaro, Marcos, comp. (2002) El derrumbe político en el ocaso de la convertibilidad. Buenos Aires,_Grupo Editorial Norma.

O’Donnell, Guillermo (1993) “Acerca del Estado, la democratización y algunos problemas conceptuales” Desarrollo Económico No 130:163-184.

OECEI (1974) La Argentina Económica y Social. Buenos Aires, Oficina de Estudios para la Colaboración Económica Internacional.

Palermo, Vicente y Novaro, Marcos (1996) Política y poder en el gobierno de Menem Buenos Aires: Grupo Editorial Norma/FLACSO.

ProvInfo (2004) Base de datos de la Unidad de Información Integrada ProvInfo. Secretaría de Provincias, Ministerio del Interior http://www.mininterior.gov.ar/provinfo/inicio.asp Actualización: 16 de febrero del 2004 - Tomado de la web: 4 de mayo de 2004

Reboratti, Carlos (1996) "Pampeanización del NOA o la adaptación al ecosistema local” en Mabel Manzanal, comp., El desarrollo rural en el noroeste argentino. Salta, Proyecto Desarrollo Agroforestal en Comunidades Rurales del Noroeste Argentino, GTZ (edición original 1986).

Rodrigo, Cintia (2011) "Notas sobre la autonomía provincial en contextos de inestabilidad política” Revista Trabajo y Sociedad No 16:125-133. 
Rofman, Alejandro (2000), Desarrollo Regional y exclusión social. Buenos Aires, Amorrortu.

Thwaites Rey, Mabel y López, Andrea (editoras) (2005) Entre tecnócratas globalizados y políticos clientelistas. Derrotero del ajuste neoliberal en el Estado argentino. Buenos Aires, Editorial Prometeo.

Videla, Horacio (1962) Historia de San Juan. Buenos Aires, Academia del Plata.

\section{Diarios}

\section{Interdiarios}

11/04/94 Escobar: "El Frente de la Esperanza representa el proyecto Nacional" 12/04/94 Escobar sostuvo que el Gobernador de San Juan debe renunciar 21/12/94 Afirman que la situación sanjuanina "está muy próxima a lo crítico" 26/12/94 Crisis en San Juan

28/12/94 Escobar asumirá en San Juan con 10 millones para pagar sueldos

27/07/95 Daniel Hadad con Raúl Benítez

27/07/95a Pepe Elisachev con Rogelio Cerdera

31/07/95 Marcelo Longobardi con Héctor Sánchez

01/08/95 Bernardo Neustadt con Jorge Escobar

04/08/95 Marcelo Bonelli con Alfredo Duarte

\section{Microsemanario}

Microsemanario Año 5 No 204 - Oficina de Prensa de la Facultad de Ciencias Exactas y Naturales - UBA - Buenos Aires //www.fcen.uba.ar/prensa/micro/1995/ms204a.htm Microsemanario" Año 5 N 206 - Oficina de Prensa de la Facultad de Ciencias Exactas y Naturales - UBA - Buenos Aires //www.fcen.uba.ar/prensa/micro/1995/ms206a.htm

\section{Página 12}

30/07/95a La base económica de la bronca

30/07/95b A merced del Zonda 